\section{BOMBARDEANDO PATRIMONIO EN EL CAMPO DE TIRO MILITAR DE EL TELENO (LEÓN): DE LA SUBLIMACIÓN DE LA NATURALEZA A LA CONSTRUCCIÓN SOCIAL DEL PATRIMONIO CULTURAL}

\author{
Pablo Alonso González \\ Universidad de Cambridge \\ pa332@cam.ac.uk \\ Alfredo Macías Vázquez \\ Universidad de León \\ amacv@unileon.es
}

\section{BOMBING HERITAGE IN THE MILITARY RANGE OF THE TELENO (LEÓN): FROM THE SUBLIMATION OF NATURE TO THE SOCIAL CONSTRUCTION OF CULTURAL HERITAGE}

Cómo citar este artículo/Citation: Alonso González, P. y Macías Vázquez, A. (2014). "Bombardeando patrimonio en el Campo de Tiro Militar de El Teleno (León): de la sublimación de la naturaleza a la construcción social del patrimonio cultural". Arbor, 190 (766): a121. doi: http://dx.doi.org/10.3989/ arbor.2014.766n 2013

Recibido: 7 febrero 2013. Aceptado: 16 diciembre 2013.

RESUMEN: Se analiza la construcción social del Campo de Tiro Militar de El Teleno como reserva natural a partir de la retórica auspiciada por el "giro ambientalista" del Ministerio de Defensa. Ante la conflictividad existente en Maragatería, esta estrategia de contención deviene en una sublimación ideológica: la posibilidad de la preservación (natural) viene dada por la reproducción necesaria de la destrucción (humana). Por su parte, las estrategias de resistencia han adoptado formas diferentes. Entre ellas, la construcción social del Teleno como patrimonio cultural socava la estrategia de sublimación del C.M.T. como "paraíso natural", mostrando la fuerte presencia humana previa en la zona. Ambas metanarrativas se han convertido en el pilar fundamental alrededor del cual se organizan las luchas simbólicas entre instituciones y activistas, lo que representa un cambio fundamental al dejar fuera a las personas y las relaciones inmanentes de las comunidades con el bosque. En ambos discursos metaculturales, se reproduce la separación entre naturaleza y cultura tan característica de la modernidad.

PALABRAS CLAVE: Militarización del Territorio; Maragatería; Patrimonio Cultural; Gestión Ambiental.
Copyright: (C) 2014 CSIC. Este es un artículo de acceso abierto distribuido bajo los términos de la licencia Creative Commons Attribution-Non Commercial (by-nc) Spain 3.0.

ABSTRACT: The paper analyses the social construction the Teleno Military Range (León, Spain) as a nature reserve as a result of the 'environmental shift' taken by the Spanish Ministry of Defence. Facing social rejection in the Maragatería region of León, the Ministry put a containment strategy in place that predicated the possibility of preservation (of nature) on the reproduction of (human) destruction. In respose, strategies of resistance built a social construct of the space that emphasised the Roman archaeological remains of the Teleno as cultural heritage. This strategy undermined the Ministry's discourse of nature conservation by highlighting the anthropisation of the area prior the establishment of the Range and underscoring the latter's pernicious effects in natural, cultural and economic terms. Both the ecological and the heritage metanarratives became the cornerstone around which symbolic struggles between institutions and activists have taken place. This represents a fundamental shift, as it leaves out human experience and the relationship between communities and forest. Ultimately, both metanarratives reproduce the modern divide between nature and culture.

KEYWORDS: Militarisation of the Territory; Maragatería; Cultural Heritage; Nature and Conservation. 


\section{INTRODUCCIÓN}

El Campo de Tiro Militar de El Teleno (C.M.T.) en la comarca de Maragatería (León) es una realidad insoslayable que subsume la población en un mismo entorno afectivo y emocional: nadie en la zona puede escapar a su existencia. Durante seis décadas, las bombas y sus explosiones han condicionado la vida de sus gentes de muchas maneras. Sin embargo, este hecho empírico, simple y contundente se vuelve indiferente en la vida cotidiana de la zona y más aún en la esfera pública y mediática. ¿Quién ha oído hablar, especialmente entre las nuevas generaciones de este país, del C.M.T. y sus devastadoras consecuencias en las comunidades locales? La indiferencia llega también a los medios académicos, donde es difícil encontrar bibliografía sobre el impacto sociocultural de los Campos Militares (Prat, 2008).

Buchli y Lucas afirman que "la producción y el consumo constituyen los polos centrales de la vida material contemporánea, siendo la base material de la vida social en las sociedades industrializadas capitalistas y socialistas" (Buchli et al., 2001: 21). González Ruibal (2008: 247) añade que, junto con el consumo y la producción, la destrucción (y su subsecuente olvido) es el rasgo más fundamental que define la modernidad: "este olvido de lo reciente no sólo es causado por la naturaleza peculiar de la supermodernidad, o la falta de profundidad temporal. Paradójicamente, el hecho de que tenemos una memoria viva del pasado reciente y que estamos involucrados personalmente en él, ha condenado a la supermodernidad al olvido. Parece que no podemos estudiar lo que nosotros -o nuestros familiares- directa o indirectamente hemos experimentado. Los acontecimientos de la supermodernidad a menudo se viven como un trauma personal y colectivo en el presente en parte debido a su naturaleza destructiva. No es fácil por tanto hablar sobre ellos, mientras que los episodios históricos más remotos -tales como la revolución de 1848 o la Guerra Franco-Prusiana por lo general han perdido el poder de afectarnos de manera tan conmovedora" (2008: 248).

En este artículo abordamos la cuestión del C.M.T. desde un punto de vista "múltiple, históricamente situado, infinitamente complejo e inmerso en sus propias contradicciones y controversias inherentes" (Ripley et al., 2009: 6). O, en palabras de Latour, como una 'cuestión de preocupación' (2004b) explorada mediante una "investigación múltiple apoyada en las herramientas de la antropología, la filosofía, la metafísica, la historia, y la sociología para detec- tar cuántos elementos están implicados en una entidad para hacerla existir y mantener su existencia" (2004a: 246). En consecuencia, hemos intentado reunir los diferentes aspectos que conectan Maragatería con el C.M.T., es decir, los diferentes discursos, actos, prácticas y respuestas que el C.M.T. ha elicitado y los subproductos que se han derivado de ellos. Uno de estos subproductos es el intento de construir el Monte Teleno como patrimonio cultural 'oficial' por parte de diferentes actores sociales, de modo que su bombardeo por parte del ejército resulte (aún más) ilegítimo. Mientras tanto, las instituciones implementan estrategias de contención con el objetivo de salvaguardar la separación entre naturaleza y cultura tanto como sea posible, para evitar que se establezca una asociación entre patrimonio cultural, vida humana y el Monte Teleno.

Existe una base objetiva que subyace en toda la cuestión: el Monte Teleno ha sido históricamente un símbolo para el territorio, ya venerado como un Dios por culturas prerromanas y romanas - el Dios Tilenus. Por otra parte, el Teleno alberga la más importante área minera aurífera del Imperio Romano, materializada en una compleja obra de ingeniería que incluye labores de extracción, canalizaciones de agua y depósitos (Matías Rodríguez, 2006). Sin embargo, lejos de estar inventariados, estudiados y puestos en valor, estos restos están siendo bombardeados por los regimientos de artillería que realizan sus maniobras militares en el C.M.T., usando el monte como 'área de caída de proyectiles'. Así las cosas, desde los años 80 la Maragatería se ha convertido en uno de los lugares centrales en la lucha por la 'desmilitarización' del territorio (Prat, 2008).

En este contexto, distintas posiciones tienen cabida y confluyen en un ámbito discursivo donde se entremezcla lo ideológico, lo económico, sociopolítico y la protección de la naturaleza. Algunos actores sociales denuncian la destrucción de la naturaleza y analizan en detalle las consecuencias del C.M.T. para la fauna (Martínez, 2000), o la contaminación que provoca en el agua y el aire. También se hace referencia a las consecuencias a largo plazo del C.M.T., ya que el acceso al área que ocupa, con sus recursos y remanentes patrimoniales se verá impedido por la abundancia de proyectiles sin detonar. Otros apuntan al ámbito de las potencialidades virtuales del área que el C.M.T. impide. Así, muchos afirman que Magaratería podría ser una zona prioritaria de desarrollo turístico. Campesinos y granjeros argumentan que el estrés causado por las bombas está detrás de los innumerables abortos 
entre sus animales y la reducción de su productividad lechera. Los menos recuerdan la existencia de un proyecto desde la década de 1920 para construir una presa en Chana de Somoza que nunca fue implementado, y culpan al C.M.T. de impedir su realización en las últimas cinco décadas. Solamente los más viejos recuerdan con tristeza la expropiación de sus bienes comunales por el Ministerio de Defensa, estableciendo en la mayoría de los casos una conexión directa entre ese acontecimiento y el fin de sus vidas productivas. El C.M.T. genera 'otra' Maragatería, una Maragatería virtual que existe en la mente de las personas, que imaginan otro pasado y otro futuro para su territorio. La imaginación, sin embargo, no impide que los proyectiles continúen cayendo en el Monte Teleno.

Nuestra metodología ha combinado la investigación histórica con la etnográfica. Desconocemos la existencia de documentación escrita sobre el tema antes de la década de 1970 ya que el C.M.T. operaba pero no existía oficialmente. A partir de 1980 se produce un alud de artículos en diversas publicaciones nacionales, regionales y locales cuando el Ministerio de Defensa revela su intención de expropiar una importante superficie de tierra en Maragatería para ampliar el C.M.T. Blogs de diversos actores sociales implicados en el conflicto también fueron consultados para contextualizar la investigación. En el contexto de una investigación doctoral de seis años de duración (Alonso González, 2013), se han realizado una veintena de entrevistas semiestructuradas y otras tantas informales con personas que tuvieron un rol prominente en la lucha contra el C.M.T. y con múltiples habitantes de la zona afectados o interesados en el mismo, incluyendo a las familias de muertos a causa del C.M.T., a lugareños que trabajaron en las tareas de extinción del incendio de Tabuyo del Monte, y a los activistas pacifistas y ecologistas. Sin embargo, pese a nuestro intento, no fue posible contactar con representantes militares ni en el cuartel de Astorga ni en el Ministerio de Defensa.

\section{EL CAMPO MILITAR DEL TELENO: ORÍGENES Y EX- PROPIACIÓN}

Los orígenes del C.M.T. se retrotraen a los tiempos de la República. Después de la Guerra Civil, todavía se encontraba en uso de manera informal. En 1963, se legalizó a través de un convenio entre el Ejército y los pueblos afectados representados por la Oficina Estatal de Preservación Forestal (Luengo Ugidos, 1994). A principios de la década de 1980 el Ejército buscó ampliar el C.M.T. en el marco de las negociacio- nes de España para unirse a la OTAN. La expropiación se anunció en el BOE el 23 de febrero de 1981. Afectó a una importante extensión de tierras de producción ganadera y agrícola ${ }^{1}$. Las Juntas Vecinales ${ }^{2}$ crearon una plataforma para luchar contra la expropiación, aunque nunca fue reconocida por el gobierno de la UCD. Como señala Fernández Fernández (en España, 12/06/1981), la medida representó una sentencia de muerte para los pueblos afectados, al jugar las propiedades comunales un papel económico fundamental en el aprovechamiento ganadero (Martín Galindo, 1958). Para Miguel, un hombre de 95 años de Valdespino de Somoza, la cuestión era clara: "aquí, en el pueblo, nos quitaron las mejores tierras. Las tierras comunales eran las mejores que teníamos, y fueron expropiadas" (Entrevista, 20 de julio de 2010).

Tomás Pollán García ${ }^{3}$ en una devastadora serie de artículos contra el C.M.T. titulada "Allanamiento de Morada" y publicada en El Faro Astorgano contrastó la supuesta 'urgencia' del proceso expropiador con la ausencia de proyectos de desarrollo en la zona. Igualmente, comparó críticamente la vehemencia mostrada por muchas personas en la exaltación del folklore maragato, especialmente en Astorga, con su escasa participación en las luchas contra la expropiación. Además, buscó desviar la atención de temas económicos para centrarse en cuestiones éticas y de dignidad, resaltando la imposibilidad de fijar un precio a "lo que está más allá de ser comprado o vendido: la tradición de un pueblo, sus tierras, la solidaridad, las creencias íntimas, la autonomía y la dignidad de los pueblos libres" (27/08/1981).

La evolución del proceso a nivel local puede trazarse en publicaciones diarias sobre el mismo en el periódico astorgano 'El Faro' durante los primeros años de la década de los 80. En ellos, resulta evidente como algunos actores sociales, como por ejemplo empresarios y el alcalde de Astorga del momento, apoyaron la expropiación argumentando que traería beneficios para la zona, asumiendo la posición oficial que consideraba la Maragatería un erial y las condiciones de vida de sus gentes como primitivas y subdesarrolladas. Discurso que evidentemente buscaba legitimar el proceso de expropiación, siendo el rol del Ejército el de traer la 'modernidad' al área. Siguiendo a Williams (1989), el estado puso en marcha un modo de comunicación paternalista, que asume un rol educador y benefactor para sus súbditos-ciudadanos, a los que trata como niños e ignorantes que desconocen qué es lo mejor para ellos. En esta estrategia retórica, se elogiaba a los maragatos como gentes valiosas cuyas con- 
diciones de vida estarían muy por debajo de lo que en realidad merecían, y que supuestamente el Ejército, como redentor, les podía ofrecer.

Sin embargo, la resistencia continuó. Distintos autores destacaron los importantes activos económicopatrimoniales de la Maragatería, los alcaldes del área dimitieron en masa y se llegó a celebrar en Astorga la primera y última manifestación que reunió a varios miles de personas procedentes de los pueblos maragatos. Martínez Veiga (1981) consideró la manifestación como un símbolo de afirmación del carácter étnico del colectivo maragato. Para él, la continuidad de la cultura maragata respecto al pasado debería buscarse en su logro de un equilibrio simbiótico con la naturaleza basada en diferentes tipos de movilidades, y no en su representación folclórica 4 .

La ampliación del C.M.T. implicó un dramático incremento de la intensidad de los bombardeos artilleros contra el Monte Teleno. Dada la localización de los puntos de tiro, los proyectiles comenzaron a volar por encima de los pueblos, las áreas de cultivo y de ganadería y de las infraestructuras. José, anciano de Boisán, considera que "hubo ahí algunos años que daba miedo, aquí no había quien estuviera... la metralla caía por todos laos (sic) ... estabas ahí con la ganadería que aquí había mucha, y daba miedo... 'va a haber que marchar de aquí, va a haber que marchar de aquí', decía mucha gente'" (Entrevista, 23 de julio de 2009). Incidentes de toda clase han sido habituales desde entonces, con dos fallecidos desde 1981. Antes de esa fecha, los datos no están claros.

En este contexto, continuaron las actividades de los municipios y Juntas Vecinales para evitar los nuevos intentos de ampliación del C.M.T. Diferentes grupos han elaborado listas detalladas de todos los daños ocurridos como consecuencia de la presencia del C.M.T., con un particular énfasis en la multitud de incendios ocurridos. Sin embargo, nuestra etnografía revela que cada pueblo tiene su propia 'historia personal' de desencuentros de distinta índole con el C.M.T.

\section{ESTRATEGIAS DE CONTENCIÓN Y ESTRATEGIAS DE RESIS- TENCIA: DE LA SUBLIMACIÓN DE LA NATURALEZA A LA CONSTRUCCIÓN SOCIAL DEL PATRIMONIO CULTURAL}

Sin embargo, tanto la ciudad de Astorga como el resto de instituciones dejaron solos a los pueblos maragatos en su causa. A partir de entonces, distintas administraciones emplearían 'estrategias de contención' para gestionar el descontento de los maragatos. Según Kearney (1996: 64), la contención no funciona mediante la transmisión de ideología falsa, sino por medio de la afirmación y la construcción de otros regímenes de verdad. Una estrategia de contención fue la creación de planes de desarrollo basados en la retórica de la sostenibilidad y el crecimiento endógeno: primero la Oficina de Promoción Regional (Cabero Diéguez, 2005) y ya en los 90 el Grupo de Acción Local de financiación europea 'Montañas del Teleno' para promover el desarrollo del turismo rural en varias comarcas, incluyendo Maragatería. Paradójicamente, ambos proyectos parecían pasar por alto los evidentes efectos disuasorios del C.M.T. para el turista. Sin embargo, esta estrategia de contención se acoplaba a la perseguida por el Ministerio de Defensa: la construcción social de los Campos Militares como reservas naturales. Este proceso revela la transición a modelos de gobernabilidad neoliberal (Rose, 1996) sobre los que descansa la retórica del 'giro ambientalista' o 'ecológico' abordado por el Ministerio de Defensa. Se enfatizan así los valores naturales evitando referencias al precio pagado por las comunidades humanas.

En el libro La Sierra de El Teleno: El campo militar de adiestramiento de El Teleno y sus condiciones ambientales (Tornero Gómez, 2005), se describe una prístina, bucólica e indemne zona llena de tradiciones, inventariando una riquísima fauna y flora que - gracias al C.M.T. - se reproduce pacíficamente. En la publicación Espacios naturales del Ministerio de Defensa se denomina a los C.M.T. 'espacios protegidos'. Múltiples expertos de la élite de la investigación española participaron en el volumen, aduciendo - entre otras cosas - que "los ecosistemas de los campos de entrenamiento y maniobra son escasamente agredidos y en ellos las especies animales y vegetales encuentran mejores condiciones de supervivencia que en otros lugares" (Varillas et al., 2006). Además, evitaban el impacto de la especulación inmobiliaria sobre la naturaleza. Estas afirmaciones han sido discutidas por Ecologistas en Acción, y esconden además que se trata en algunos casos, como en Maragatería, de zonas humanizadas y escasamente 'naturales'.

En realidad, las reservas naturales son por excelencia los representes máximos de la moderna separación epistémica y ontológica entre naturaleza y cultura, ya que son espacios designados para ser 'naturaleza' por el hombre. Más aún los campos militares, espacios que sirven para depurar las tecnologías de exterminio de otros seres humanos -aunque igualmente el giro neoliberal emplee la retórica del 'mantenimiento de la paz'. En última instancia, la paradoja de esta estra- 
tegia de contención deviene en una sublimación ideológica: la posibilidad de la preservación (natural) viene dada por la reproducción necesaria de la destrucción (humana). Para ello es necesario que, como plantea Freud (2005 [1930]), se produzca una sublimación, es decir, la transformación consciente de impulsos o prácticas socialmente inaceptables en aceptables.

Por su parte, las estrategias de resistencia han adoptado diferentes formas. Algunas han seguido la epistemología de la crítica moderna, al estilo de Chomsky y que alcanza su culmen con la deconstrucción derrideana (Žižek, 2004). Esta concepción considera que desafiar a las narrativas oficiales implica oponerse a ellas con todo tipo de datos disponibles y produciendo narrativas alternativas más completas (González-Ruibal, 2008). Pacifistas y ecologistas han seguido esta estrategia durante décadas. La más activa organización contra el C.M.T. en este sentido ha sido AEDENAT y la Plataforma por el Desmantelamiento del Campo de Tiro del Teleno (1999). En 1985, crearon la Casa por la Paz en el centro neurálgico del C.M.T., Quintanilla de Somoza, desde donde organizan distintas actividades pacifistas. También han impulsado la constitución de cooperativas de miel y frutas del bosque para buscar soluciones económicas alternativas y demostrar la viabilidad del territorio. Igualmente, han realizado denuncias por vía penal y en distintos medios de comunicación, realizado charlas, caminatas por el campo, recolección de materiales militares, estimaciones de daños ecológicos, culturales y económicos, análisis de contenidos venenosos en proyectiles e impacto del ruido en la población, entre otras muchas acciones (ver Ecologistas en Acción, 2007 para una síntesis). Todas ellas articulaban de formas diversas el discurso crítico contra el C.M.T.

Por otro lado, Foucault, y especialmente Deleuze, proporcionan otra estrategia sobre la verdad que no descansa necesariamente en la crítica dialéctica negativa, sino en la construcción positiva de narrativas no necesariamente basada en datos científicos (Bell, 2008). Algunos intelectuales, a los que se han unido ecologistas y pacifistas, han seguido este enfoque, que implica la construcción social del Teleno como patrimonio cultural. Domergue y Hérail ya subrayaban hace décadas la relevancia de los restos arqueológicos en Maragatería y el Monte Teleno, advirtiendo que allí se encuentra el área minera romana más grande a nivel mundial conocida hasta la fecha (1978). Esta estrategia es complementaria a la anterior, y presenta un carácter positivo y constructivo que permite flanquear la retórica discursiva empleada por el Ministe- rio de Defensa que pretende erigirse como 'defensor de la naturaleza' como si este fuese el punto en cuestión. Esta estrategia gana apoyos en la sociedad y medios de comunicación locales ante la ausencia de 'discursos patrimoniales autorizados' (Smith, 2006) por parte de instituciones públicas - Diputación de León y Junta de Castilla y León - y entidades semipúblicas de gobernanza técnica neoliberal - proyecto LEADER - que simplemente miran hacia otro lado. Finalmente, es funcional porque socava la estrategia de sublimación del C.M.T. como 'paraíso natural', mostrando la fuerte presencia humana previa en la zona. En la práctica, ambas estrategias se mezclan y se combinan con todos los argumentos posibles contra el C.M.T.

En síntesis, el intento de construcción social del Teleno como patrimonio cultural oficial busca su clasificación, inventario y reconocimiento oficial, lo que implicaría una serie de obligaciones morales y legales que socavarían la legitimidad del C.M.T. (Carman, 2002: 22). Diversas iniciativas se pusieron en marcha en esta dirección que exceden el ámbito de este artículo. En ellas podemos incluir iniciativas políticas que buscaban reconocimientos oficiales para el patrimonio arqueológico de la Maragatería, en especial los castros de la Edad del Hierro y Romanos, y con más fuerza intentos académicos por evidenciar, a partir de estudios empíricos, el potencial del Teleno en sí mismo como zona arqueológica de explotación del hierro en época romana. Estos llamamientos tuvieron su plasmación en publicaciones (ver Matías Rodríguez, 2006 para un estado de la cuestión), y también gozaron de difusión pública por la celebración de un congreso sobre minería aurífera romana en Astorga en 2006 con gran repercusión mediática. No obstante, las múltiples iniciativas en esta dirección han fracasado. El desagravio es evidente cuando se compara con regiones cercanas, como Las Médulas, cuyas minas romanas fueron declaradas Patrimonio de la Humanidad (1997) por la UNESCO. Dentro de la idea de bien universal de la humanidad Las Médulas resultan aproblemáticas: son estéticamente agradables y su valorización no plantea problemas éticos. Pese a que, desde un punto de vista científico, el complejo minero del Teleno - que se encuentra intrínseca y estructuralmente conectado al de las Médulas - es de similar interés, su declaración ni si quiera se plantea o se saca a colación durante el proceso de declaración: el patrimonio sirve como instrumento de gobernabilidad que permite enmascarar cuestiones problemáticas.

Con estos precedentes, el Teleno y Maragatería se están convirtiendo gradualmente en futuros luga- 
res de 'patrimonio negativo', depósitos de memoria negativa en el imaginario colectivo (Meskell, 2002: 558). Sin embargo, para los lugareños, el C.M.T. y sus daños asociados están lejos de ser "lugares de memoria" (Nora, 1989), siendo más bien una realidad a enfrentar diariamente. Lamentablemente, la incorporación del C.M.T. en el 'paisaje imaginado' de las comunidades locales y el potencial de movilización de los recuerdos negativos de la zona para fines didácticos positivos resulta complicado. Si "el patrimonio es algo que puede ser transmitido de una generación a la próxima" (Harrison, 2010: 13), el C.M.T. será una herencia negativa: aunque fuese desmantelado, los residuos de los proyectiles y metales y la contaminación ambiental permanecerán como evidencia material de la destrucción. En Teleno, la lógica patrimonial se invierte. Normalmente, muchas cosas se clasifican como patrimonio ante el riesgo de perderlas (Harrison, 2010: 17). Por el contrario, la ausencia racional y premeditada de un discurso patrimonial autorizado funciona como soporte a una estrategia de contención que busca construir el C.M.T. como un espacio natural que protege y fomenta la vida.

En todo caso, cabe resaltar que las metanarrativas retóricas patrimoniales y ecologistas se han convertido en el pilar fundamental alrededor del cual se organizan las luchas simbólicas entre instituciones y activistas, lo que representa un cambio fundamental: al referirse prioritariamente a entes culturales y naturales, ambas partes están dejando fuera a las personas. Sorprendentemente, las muertes humanas o las expropiaciones de propiedades comunales pasan a un segundo plano respecto a aves y minas romanas. La cultura es entonces concebida más de forma limitada como metacultura que como una definición antropológica amplia que incluiría la vida humana en sus diversos aspectos (Geertz, 1992). Así, al enmarcar la cuestión en términos simbólicos de patrimonio y naturaleza no sólo se abandona la lucha real por la simbólica, sino que se reproducen binarismos epistemológicos modernos: tanto la estrategia de contención como la de resistencia construyen naturaleza y la cultura en el Teleno como discursos metaculturales desconectados de las personas en Maragatería.

\section{¡LOS BOSQUES SON NATURALEZA! EL BOSQUE DE TABUYO DEL MONTE Y EL INCENDIO DE 1998}

Los lazos entre las comunidades preindustriales y sus bosques, que eran total o parcialmente de propiedad comunal (Álvarez, 2005), eran fuertes y necesarios por su reproducción económica. En el caso de Tabuyo, esta relación era más intensa debido al rentable sistema comunal de extracción de resina en funcionamiento desde finales del siglo XIX. Desde los 80 , la actividad económica giró en torno a la producción forestal al decaer el negocio de la resina (Sandín Pérez, 2008).

En septiembre de 1998, dos misiles estallaron en el bosque de Tabuyo provocando un incendio que arrasó 4000 hectáreas $^{5}$. El fuego redujo al mínimo los recursos comunales (setas, caza, madera, resina) para los siguientes cuatro décadas, al menos. Tuvo una especial significación por el valor económico del bosque, pero también por el apego emocional de la comunidad con el mismo, y por las consecuencias políticas que implicó. Entre las entrevistas realizadas, destaca la mantenida con cinco personas ${ }^{6}$ que participaron en los trabajos de extinción. Al preguntarles por los sentimientos de la gente del pueblo ante lo ocurrido se evidencia que los recuerdos afectivos de estas comunidades se encuentran en relación inmanente con el valor funcional y económico que perciben en su medio. Los entrevistados no culpaban solamente a las Fuerzas Armadas, sino fundamentalmente al marco regulatorio que encuadra las relaciones entre el pueblo y sus bosques. Comparaban cómo son hoy las cosas con cómo eran en el pasado, destacando los peligros que acarrean las modernas técnicas de extinción y la gestión tecnificada del bosque desconectada de la comunidad. Claramente, se ponía de manifiesto que las comunidades locales están lejos de ser ignorantes y retrógradas como la administración pretende dar a entender. En realidad, poseen un conocimiento profundo del bosque, de las modernas técnicas de prevención y de explotación forestal. A la vez, su visión funcional del bosque no excluye la generación de sólidos lazos emocionales con él. Al contrario, los vínculos se crean inmanentemente sin separar naturaleza y cultura, ni cultura y economía: para ellos la relación con el bosque no es metacultural o articulada en términos de patrimonio, sino como parte inmanente de sus formas de vida. Mientras que la racionalidad moderna se impone sobre la gestión de los bosques y el control científico de los incendios conduce a un gradual incremento de los gastos en extinción, la perspectiva de las comunidades locales aborda la cuestión fundamental de cómo relacionarse con la naturaleza, concibiendo las tareas de prevención como algo que debe ser realizado por ellos mismos. La interrupción trascendente por parte de los técnicos del Estado de las relaciones inmanentes entre la comunidad y el bosque es el resultado de la construcción moderna de la naturaleza como un reino independiente de la vida humana. Con 
el dinero público que se gasta en extinción ${ }^{7}$, las comunidades rurales tendrían recursos suficientes para reproducir sus costumbres tradicionales y sus modos de vida, lo que posiblemente sería más efectivo para impedir la difusión del fuego (prevención).

Tras el incendio, nada ha cambiado sustancialmente. Astorga continúa apoyando el C.M.T. porque se considera que de ello depende el mantenimiento de los cuarteles en la ciudad, mientras los pueblos de Maragatería siguen rechazándolo en gran medida. Paralelamente, pese a que disminuyó la intensidad de los bombardeos ante la evidencia de la magnitud de la catástrofe, la aproximación institucional al tema tampoco cambió siguiendo en sintonía con lo que Cazorla llamó el universalismo en protección forestal (1984). En el Seminario de restauración de áreas afectadas por grandes incendios: el caso de El Teleno (Ruiz Pérez y Rey van den Bercken, 2005), el debate giró en torno a los aspectos técnicos y científicos desde la perspectiva disciplinaria de la biología y la ecología. Todas las contribuciones daban cuenta del incendio como un 'fallo técnico', construyéndolo socialmente como una consecuencia de causas naturales - el viento - sin siquiera mencionar lo que todos saben: que fue causado por proyectiles del C.M.T. Se justificaron las medidas técnicas tomadas en las tareas de extinción, considerando el incendio y sus consecuencias devastadoras como un acontecimiento desafortunado. Claramente, "Ios expertos científicos continúan viendo la naturaleza como superior a la cultura, las alteraciones humanas como inferior al fundamento prístino previo" (Lowenthal, 2005: 87).

El discurso subyacente forma parte de la estrategia de contención: al tratarse del ámbito de lo natural podemos aplicar dispositivos científicos para reconstruirla. En esta lógica, el pueblo de Tabuyo debe sentirse afortunado ya que su bosque está sometido a los últimos experimentos en técnicas de reforestación de alta tecnología. ¿Por qué molestarse en repensar los problemas estructurales que afectan a la zona y la gestión forestal? Al enmarcar el debate sobre la restauración del bosque como una cuestión científicotécnica propia de expertos, se excluye a la comunidad local (considerada ignorante) y se encubre el progresivo fortalecimiento de los intereses corporativos de las industrias forestales y de extinción en los entornos rurales (Seijo, 06/08/2012).

Tampoco se menciona la 'otra' restauración, la que se relaciona con el apego emocional que conecta a la comunidad local con el bosque. No solo la 'pérdida', tanto colectiva como individual, es un proceso com- plejo de consecuencias imprevisibles (Marris, 1974), sino que la reconstrucción física no implica la mental y la cultural (Viejo-Rose, 2011). Nadie se interesa en lo que el bosque significa para el pueblo, ni por la relación existente entre el pueblo y el C.M.T. ¿Por qué? Porque tanto el C.M.T. como el bosque son construidos por el discurso hegemónico del ensamblaje de poder-conocimiento - Estado y expertos - como 'naturaleza'. Consecuentemente, la comunidad local - legítima propietaria del bosque - tiene un escaso papel en cuestiones de gestión al carecer de los medios científico-técnicos de los expertos. Este lamentable asalto abierto sobre la dignidad, los derechos y la inteligencia de la población local se ve reforzada por la combinación de discursos académicos, cívicos y militares. Una vez más se reproduce la secular conceptualización del 'campesino rural' por parte del Estado español como sujeto incompetente, atrasado e ignorante (Aceves, 1978).

\section{CONCLUSIONES}

Los ámbitos de la cultura y la naturaleza son percibidos separadamente y asociados a formas de actuación distintas desde la modernidad. Sin embargo, estas categorías y su conceptualización es variable, especialmente en comunidades rurales íntimamente ligadas a la naturaleza que las rodea. Pese a la creciente tendencia internacional a la integración de cultura y naturaleza (Rössler, 2003) los Estados nacionales, en este caso el español, parecen reacios a dar un paso que reduciría su margen de actuación. La cuestión del C.M.T. puede ser entendida como una lucha por la imposición de un determinado 'régimen de verdad' (Foucault y Gordon, 1980). El Ministerio de Defensa ha pasado de una posición arrogante y agresiva a otra más abierta caracterizada por una presunta voluntad de establecer relaciones constructivas y dialogantes con otros actores sociales. Para ello, emplea la retórica de la 'preservación de la naturaleza' para justificar el mantenimiento de los campos militares a lo largo de España. Esta estrategia de contención es efectiva cuando, como en el C.M.T. y en el bosque de Tabuyo, "es capaz de constituir los tipos que esencializa" (Kearney, 1996: 64). A través de múltiples vectores (publicaciones, medios de comunicación, apoyos académicos e institucionales, discursos oficiales y legislación), se separa la naturaleza de la cultura y se transmite la idea de que los campos militares son positivos para la vida natural. Así, se invierte la lógica del sentido común y se construye socialmente a los campos militares como reductos donde la naturaleza es protegida de la destrucción provocada por la ci- 
vilización moderna. Esta estrategia está orientada a la ocultación y deslegitimación de las estrategias de resistencia: ante la opinión pública tanto activistas como comunidades ya no luchan contra la militarización sino contra la 'ética ecologista' encarnada por el Ministerio de Defensa. En esta línea, la incorporación de científicos y académicos de alto rango en sus discursos es parte de lo que Latour llama estrategias de "rectificación e institucionalización" (2007) y de "blackboxing" (1999), mediante las cuales se impone subrepticiamente un discurso científico y se familiariza a la gente gradualmente con un estado de cosas hegemónico, un régimen de verdad.

Nuestro estudio revela dos patrones diferentes de ordenar historias (Law, 2004: 111). La oficial es incremental, evolutiva y poco dramática. Los acontecimientos se desarrollan poco a poco, los problemas surgen y se resuelven. El segundo patrón es el transmitido por comunidades locales y activistas, un sub-texto (Scott, 1990) cuya memoria es preservada a través de la transmisión oral y que rara vez alcanza la esfera pública o es capaz de construir un régimen público de verdad. Este patrón de narración es heroico, romántico y discontinuo, y concibe el cambio en términos cualitativos. Los activistas y algunos actores políticos y sociales en Maragatería han luchado contra el C.M.T. de diversas maneras y por medio de diferentes estrategias: desde la chomskiana revelación de verdades alternativas, que descubre todas las trampas y mentiras del C.M.T. y la retórica del Ejército, hasta la construcción positiva del Monte Teleno y Maragatería como un objeto patrimonial, dentro de un conflicto más amplio por la desmilitarización del territorio que raramente alcanza la esfera pública.

En contraste con el cercano sitio de Las Médulas (Patrimonio de la Humanidad), la gente en Maraga- tería tiene que presenciar cómo sus activos culturales son subestimados y su destrucción oficialmente sancionada y tolerada. Pese a la supuesta tarea de la UNESCO de proteger los lugares y monumentos de significación universal, las designaciones de Patrimonio de la Humanidad de facto se basan en las tradiciones patrimoniales nacionales, reproduciendo, ampliando y expandiendo sus lógicas e infraestructuras (De Cesari, 2010). Por otro lado, si tenemos en cuenta la proximidad de la bimilenaria Astorga y su enorme potencial arqueológico, a nadie se le debería escapar la posibilidad de valorización patrimonial que ofrece la construcción de un parque cultural integrador.

Por tanto, aunque la lógica de la construcción patrimonial se haya invertido en el Teleno, con activistas construyendo patrimonio y el Estado impidiéndolo, continúa la imposición fundamental de los modelos trascendentes que rompe la relación inmanente de las comunidades locales y su entorno. En lugar de partir de la inseparabilidad espiritual de la cultura tradicional y del entorno natural, se considera al sujeto rural un peligro tanto para la preservación natural y cultural. En conclusión, los 'términos del debate', el juego del lenguaje y el régimen discursivo que se ha impuesto es el del patrimonio como construcción metacultural. No importa que hayan muerto personas, que los pueblos hayan perdido sus recursos comunales, o que el potencial para el desarrollo alternativo en la zona se haya visto reducido. Lo que se discute ahora es si Maragatería y el Teleno son patrimonio o no, y su potencial como recursos económicos. Mientras tanto, el drenaje demográfico y económico continúa, y los habitantes de Maragatería - como la gran mayoría de gentes rurales - siguen siendo menospreciados, ignorados y apartados de las decisiones fundamentales para su futuro. 
1 La nueva expropiación afectó a los pueblos comprendidos dentro del área de alcance de los proyectiles: Priaranza (13 $\left.\mathrm{Km}^{2}\right)$, Quintanilla $\left(13 \mathrm{Km}^{2}\right)$, Filiel $(11,5$ $\left.\mathrm{Km}^{2}\right)$, Boisán $\left(18 \mathrm{Km}^{2}\right)$ y Luyego $\left(4 \mathrm{Km}^{2}\right)$. La suma total alcanzó $61 \mathrm{Km}^{2}$ de los aproximadamente $550 \mathrm{Km}^{2}$ de Maragatería.

2 Órganos locales antiguamente conocidos como concejos que gestionan propiedades comunales y no están supeditados a la administración de los ayuntamientos públicos.

3 A raíz de su oposición al C.M.T. y de su crítica del proceso, el profesor de la
Universidad Autónoma Tomás Pollán fue la primera persona condenada por razones políticas durante el período democrático por presuntas calumnias al estamento militar. Su condena provocó una oleada de muestras de apoyo.

4 En nuestra opinión, enfatiza excesivamente el nivel de conciencia del pueblo maragato acerca de su identidad colectiva en el tiempo. En el fondo, los maragatos se han construido socialmente desde el exterior y sus filiaciones sociales no difirieron mucho de la de otros grupos sociales provenientes de la España preindustrial: un fuerte apego a la tierra y la concepción del 'otro' como un elemento extraño.

5 En 2012 otro incendio ha arrasado otras 10.000 hectáreas, afectando parcialmente a Tabuyo.

6 Los entrevistados prefirieron mantenerse en el anonimato por lo contencioso del asunto.

7 El Estado español consume en extinción los mismos recursos que el gobierno federal de EEUU.

\section{BIBLIOGRAFÍA}

Aceves, J. B. (1978): “Olvidados por Madrid: Notas sobre la planificación del desarroIlo rural en España", en J. B. Aceves y W. A. Douglass, (eds.), Los aspectos cambiantes de la España rural, Barcelona: Barral, pp. 229-238.

Alonso González, P. (2013): The Heritage Machine: A Heritage Ethnography in Maragatería (Spain), Universidad de León, No publicada.

Álvarez, J.A.S. 2005. "La defensa del comunal y de los usos colectivos, León (18001936): ¿una "economía moral»?". Historia agraria, 37, pp. 431-463.

Bell, J. A. (2008): Between individualism and socialism: Deleuze's micropolitics of desire [Online]. Disponible: http://www2.selu.edu/Academics/ Faculty/jbell/micropolitics.pdf [Acceso $20-01-2011$ ].

Buchli, V., Lucas, G. y Cox, M. (2001): Archaeologies of the contemporary past, London, New York: Routledge.

Cabero Diéguez, V. (2005): “Región y provincia, hoy frente a los desequilibrios territoriales", Treballs de la Societat Catalana de Geografia, 17, pp. 91-95.

Carman, J. (2002): Archaeology and heritage: an introduction, London, New York: Continuum.

Cazorla Pérez, J. (1984): El clientelismo de partido en España ante la opinión pública. El medio rural, la Administración y las empresas [Online]. Dispo- nible: http://ddd.uab.cat/pub/worpap/1994/hdl_2072_1382/ICPS86.pdf [Acceso 20-04-2012].

De Cesari, C. (2010): “World Heritage and mosaic universalism", Journal of Social Archaeology, 10(3), pp. 299 - 324.

Domergue, C. y Hérail, G. (1978): Mines d'or romaines d'Espagne: le district de La Valduerna (León): étude geomorphologique et archéologique: ouvrage publié avec le consours du CNRS, Toulouse: Université de Toulouse.

Ecologistas en Acción, (2007): Denuncia de la certificación UNE en ISO 140011996 al campo de tiro de "El Teleno" (León), consultado el 20 de Marzo de 2011 en http://www.ecologistasenaccion.org/ IMG/pdf_Informe_ISO_14001_Leon.pdf

España. (12/06/1981): Boletín oficial de las Cortes Generales, Congreso de los Diputados, I Legislatura, n. 677-I.

Foucault, M. y Gordon, C. (1980): Power/ knowledge: Selected interviews and other writings, 1972-1977, New York: Pantheon Books.

Freud, S. y Strachey, J. (2005 [1930]): Civilization and its discontents, New York: W.W. Norton \& Company.

Geertz, C. (1992): La interpretación de las culturas, Barcelona: Gedisa.

González-Ruibal, A. (2008): "Time to destroy", Current Anthropology, 49(2), pp. 247-279.
Harrison, R. (2010): "What is heritage?", en R. Harrison (ed.), Understanding the politics of heritage, Manchester: Manchester University Press, Open University, pp. 5-42.

Kearney, M. (1996): Reconceptualizing the peasantry: anthropology in global perspective: Westview Press.

Latour, B. (1999): Pandora's hope: essays on the reality of science studies, Cambridge, MA.: Harvard University Press.

Latour, B. (2004a): Politics of nature: how to bring the sciences into democracy, Cambridge, MA.: Harvard University Press.

Latour, B. (2004b): "Why has critique run out of steam? From matters of fact to matters of concern", Critical inquiry, 30(2), 225-248.

Latour, B. (2007): "A textbook case revisited: knowledge as mode of existence", en Jasanoff and Society for Social Studies of Science (eds.), The handbook of science and technology studies, Cambridge: MIT Press, pp. 83-112.

Law, J. (2004): After method: mess in social science research, London, New York: Routledge.

Lowenthal, D. (2005): "Natural and cultural heritage", International Journal of Heritage Studies, 11(1), pp. 81-92.

Luengo Ugidos, M. A. (1994): "Las condiciones físicas del terrazgo en la Maragatería y su relación con el abandono de las tie- 
rras", en El medio rural español: cultura, paisaje y naturaleza: homenaje a don Ángel Cabo Alonso, Vol. 1, pp. 133-140.

Marris, P. (1974): Loss and change, New York: Pantheon Books.

Martín Galindo, J. L. (1958): "Actividades agrícolas y ganaderas en Maragatería", Estudios geográficos, 19(70), 55-85.

Martínez, M. (2000): “El campo de tiro del Teleno y su influencia en las aves de la Maragatería", Argutorio: revista de la Asociación Cultural "Monte Irago", 4, p. 48.

Martínez Veiga, U. (1981): "Etnicidad y nacionalismo", Documentación Social: Revista de Estudios Sociales y Sociología Aplicada (45), pp. 11-28.

Matías Rodríguez, R. (2006): “La minería aurífera romana del noroeste de Hispania: ingenieria minera y gestión de las explotaciones auríferas romanas en la Sierra del Teleno (León-España)", en I. Moreno Galli, (ed.), Nuevos elementos de ingeniería romana: III Congreso de las Obras Públicas Romanas, Astorga: Consejería de Cultura y Turismo, pp. 213-263.

Meskell, L. (2002): “Negative heritage and past mastering in archaeology." Anthropological Quarterly, 75(3), pp. 557-574.

Nora, P. (1989): "Between memory and history: Les lieux de mémoire", Representations, 26, pp. 7-24.

Plataforma por el desmantelamiento del campo de tiro del Teleno, (1999): “E
Teleno: armas contra la naturaleza y el desarrollo rural", Ecología política, 17, pp. 149-159.

Pollán García, T. (27/08/1981: “Allanamiento de morada II. La falacia de los beneficios económicos", El Faro, pp. 2-3.

Prat, E. (2008): “Luchas por la desmilitarización del territorio", Viento sur: por una izquierda alternativa, 96, pp. 103-113.

Ripley, C., Thuen, G. y Velikov, K. (2009): "Matters of concern", Journal of Architectural Education, 62(4), pp. 6-14.

Rose, N. (1996): "Governing "advanced" liberal democracies", en Sharma and Gupta (eds.), The Anthropology of the State: A Reader, Malden, MA: Blackwell, pp. 144-62.

Rössler, M. (2003): “Linking Nature and Culture: World Heritage Cultural Landscapes", en UNESCO World Heritage Centre (ed.), UNESCO World Heritage papers 7: Cultural Landscapes: the Challenges of Conservation, Paris.

Ruiz Pérez, I. y Rey van den Bercken, E. (2005): "Los incendios forestales en los Montes del Teleno en el período 1983-2002", en Consejería de Medio Ambiente (ed.), Seminario de Restauración de Áreas Afectadas por Grandes Incendios. El caso particular del Teleno, León: Junta de Castilla y León, pp. 55-72.

Sandín Pérez, J. M. (2008): “Lo que el fuego se llevó, 10 años del incendio que calci- nó el" Pulmón" del Teleno", Argutorio: revista de la Asociación Cultural "Monte Irago", 21, pp. 65-69.

Scott, J. C. (1990): Domination and the arts of resistance: Hidden transcripts, New Haven: Yale University Press.

Seijo, F. (06/08/2012): "El uso inteligente del fuego en el monte", Consultado el 10 de Septiembre 2012 en http://blogs. publico.es/dominiopublico/5612/

Smith, L. (2006): Uses of heritage, London: Routledge.

Tornero Gómez, J. (2005): La Sierra de El Teleno: el campo militar de adiestramiento de El Teleno y sus condiciones ambientales, Madrid: Ministerio de Defensa, Secretaría General Técnica.

Varillas, B., Sánchez Alonso, C. y García Canseco, V. (2006): Espacios naturales del Ministerio de Defensa, Madrid: Ministerio de Defensa, Secretaría General Técnica.

Viejo-Rose, D. (2011): Reconstructing Spain: Cultural Heritage and Memory After Civil War, Sussex: Academic Press.

Williams, B. F. (1989): “A class act: anthropology and the race to nation across ethnic terrain", Annual review of anthropology, 18, pp. 401-444.

Žižek, S. (2004): Organs without bodies: Deleuze and consequences, New York, London: Routledge. 